\title{
Soil water migration in the unsaturated zone of semiarid region in China from isotope evidence
}

\author{
Yonggang Yang ${ }^{1,2}$ and Bojie $\mathbf{F u}{ }^{2}$ \\ ${ }^{1}$ Institute of Loess Plateau, Shanxi University, Taiyuan, Shanxi, 030006, China \\ ${ }^{2}$ Research Center for Eco-Environmental Sciences, Chinese Academy of Sciences, Beijing, 100085, China \\ Correspondence to: Bojie Fu (bfu@rcees.ac.cn)
}

Received: 21 October 2016 - Discussion started: 11 November 2016

Revised: 19 February 2017 - Accepted: 20 February 2017 - Published: 24 March 2017

\begin{abstract}
Soil water is an important driving force of the ecosystems, especially in the semiarid hill and gully region of the northwestern Loess Plateau in China. The mechanism of soil water migration in the reconstruction and restoration of Loess Plateau is a key scientific problem that must be solved. Isotopic tracers can provide valuable information associated with complex hydrological problems, difficult to obtain using other methods. In this study, the oxygen and hydrogen isotopes are used as tracers to investigate the migration processes of soil water in the unsaturated zone in an arid region of China's Loess Plateau. Samples of precipitation, soil water, plant xylems and plant roots are collected and analysed. The conservative elements deuterium (D) and oxygen $\left({ }^{18} \mathrm{O}\right)$ are used as tracers to identify variable source and mixing processes. The mixing model is used to quantify the contribution of each end member and calculate mixing amounts. The results show that the isotopic composition of precipitation in the Anjiagou River basin is affected by isotopic fractionation due to evaporation. The isotopic compositions of soil waters are plotted between or near the local meteoric water lines, indicating that soil waters are recharged by precipitation. The soil water migration is dominated by piston-type flow in the study area and rarely preferential flow. Water migration exhibited a transformation pathway from precipitation to soil water to plant water. $\delta^{18} \mathrm{O}$ and $\delta \mathrm{D}$ are enriched in the shallow $(<20 \mathrm{~cm}$ depth) soil water in most soil profiles due to evaporation. The isotopic composition of xylem water is close to that of soil water at the depth of $40-60 \mathrm{~cm}$. These values reflect soil water signatures associated with Caragana korshinskii Kom. uptake at the depth of 40-60 cm. Soil water from the surface soil layer $(20-40 \mathrm{~cm})$ comprised $6-12 \%$ of plant xylem water, while soil water at the depth of $40-60 \mathrm{~cm}$
\end{abstract}

is the largest component of plant xylem water (ranging from 60 to $66 \%$ ), soil water below $60 \mathrm{~cm}$ depth comprised 8-14\% of plant xylem water and only $5-8 \%$ is derived directly from precipitation. This study investigates the migration process of soil water, identifies the source of plant water and finally provides a scientific basis for identification of model structures and parameters. It can provide a scientific basis for ecological water demand, ecological restoration, and management of water resources.

\section{Introduction}

Water in the soil environment plays a crucial role as a carrier of dissolved and solid species and as a reservoir in the hydrological cycle. Soil water represents a small proportion (only $0.05 \%$ ) of the hydrological cycle, but it is vital for ecosystems and affects spatial and temporal processes at different scales (Koeniger et al., 2016; Busari et al., 2013). Understanding soil water migration in the unsaturated zone is essential to describe the movement of salt, carbon, nitrogen and other nutrients. Soil water migration plays an important role in the processes of infiltration, evaporation, transpiration and percolation, hydraulic conductivity and water uptake capacity of soils in the unsaturated zone. The traditional methods have been carried out to study the movement of soil water such as hydrologic experiments, intensive observations, modeling and remote sensing (Luo et al., 2013; Yang et al., 2013; Carucci et al., 2012). However, soil water migration is a complex nonlinear and inhomogeneous flow process. It is difficult to model on the basis of Darcy's law exclusively or using other techniques. Climatic conditions, soil texture and 
structure, antecedent moisture and vegetation cover exert influence on the movement of soil water (Bose et al., 2016; Kidron and Gutschick, 2013).

Isotopic tracers can provide valuable information on complex hydrological problems, such as the runoff processes, residence time, runoff pathway and the origin and contribution of each runoff component (Arny et al., 2013; Ohlanders et al., 2013; Yang et al., 2012a; McInerney et al., 2011; Maurya et al., 2011; Kevin et al., 2010). The isotopes of $\mathrm{D}$ and ${ }^{18} \mathrm{O}$ are conservative and do not react with clay minerals and other soil materials. $\mathrm{D}$ and ${ }^{18} \mathrm{O}$ are widely used to investigate ecological and hydrological processes. Stable isotopes can provide information about mixing, transport processes and residence time of water within a soil profile in the unsaturated zone.

Different flow mechanisms result in different isotopic profiles. Stable isotope compositions of soil water, plant xylems and precipitation can be obtained to identify soil water migration processes such as infiltration, evaporation, transpiration and percolation (Caley and Roche, 2013; Yang et al., 2012b; Catherne et al., 2010; Stumpp et al., 2009). Zimmerman et al. (1967) first applied stable isotopes to study the soil water profile, showing that evaporation at the surface of a saturated soil column causes deuterium enrichment near the surface that decreases exponentially with depth. Robertson and Gazis (2006) studied the seasonal trends of oxygen isotope composition in soil water fluxes at two sites along the climate gradient. The hydrogen and oxygen isotopes are used to study the transforming of precipitation, soil water and groundwater of typical vegetation in area of the Taihang Mountains (Song et al., 2009). Gazis and Feng (2004) compared the oxygen isotope compositions of precipitation and soil water from profiles at six sites with different soil textures. $\delta \mathrm{D}$ and $\delta^{18} \mathrm{O}$ in soil water have been observed in many studies, including column experiments using sand or soil columns and field observations of unsaturated soils (Singh, 2013; Návar, 2011; Brodersen et al., 2015; Gehrels et al., 1998).

Stable isotopes provide evidence for assessing plant water sources according to their variations caused by equilibrium and kinetic isotopic fractionation mechanisms (Orlowski et al., 2016a; Haverd et al., 2011; Zhao et al., 2013; Bhatia et al., 2011). Several studies (Liu et al., 2013; Mathieu and Bariac, 1996; Allison and Barnes, 1985) have shown that transpiration do not cause isotopic fractionation of soil water. The isotopes $\delta \mathrm{D}$ and $\delta^{18} \mathrm{O}$ can be a powerful tool to determine the water sources utilized by plants in the field, since $\delta \mathrm{D}$ and $\delta^{18} \mathrm{O}$ values of xylem water reflect those of the water sources utilized (Gierke et al., 2016; Yang et al., 2011; $\mathrm{Lu}$ et al., 2011). The naturally occurring vertical gradients of $\delta \mathrm{D}$ and $\delta^{18} \mathrm{O}$ in soil water provide similar information about plant water uptake depth from soils. A number of studies have used isotopes to characterize soil water movement in one location and thus one climatic regime (Orlowski et al., 2016b; Manzoni et al., 2013; Liu et al., 2011; Stumpp et al., 2009).

Soil moisture is an important driving force of ecosystems, especially in the northwestern Loess Plateau. Characterized by dry climate, less precipitation, more evaporation and thicker soil layers, groundwater in this region is difficult to use due to the depth of water table. Thus, soil water is almost the only water resource in the study area, and has become the only factor controlling agricultural production and ecological restoration. It is necessary to investigate the mechanism of soil water migration in the Loess Plateau. Stable isotopes can provide valuable information on the mechanism of soil water migration. At present, much research focuses on the soil water recharge by precipitation and its isotope variation characteristics. There is some research on the interaction of soil water, plant water and precipitation. These studies are mostly on the individual scale in one specific region (Lin and Horita, 2016; Heathman et al., 2012; William and Eric, 2010; Ferretti et al., 2003). However, the research on the migration process of soil water, plant water, precipitation and groundwater in the unsaturated zone based on the isotopic technique is still rare. At present, the mechanism of soil water migration in the Loess Plateau is a key scientific problem to be solved.

Therefore, this study investigates soil water migration processes in the unsaturated zone in the hill and gully region of Loess Plateau using isotopes, integrated with sampling in the field, experimental observations and laboratory analysis. Samples include the soil water, plant xylem and root, etc. The objectives of this research are (1) to probe the migration process and variation of plant water, soil water and precipitation and (2) to identify each potential water source uptake by plant, and evaluate their contributions of each potential water source in the unsaturated zone. It can provide a scientific basis for ecological water demand, ecological construction, and management of water resources.

\section{Materials and methods}

\subsection{The experimental site}

The study area is located in the Anjiagou River basin in area of the city of Dingxi, China, at $34^{\circ} 26^{\prime}-35^{\circ} 35^{\prime} \mathrm{N}$ and $103^{\circ} 52^{\prime}-104^{\circ} 39^{\prime} \mathrm{E}$. The climate is semiarid, with an average annual temperature of $6.3^{\circ}$. The annual mean precipitation is $420 \mathrm{~mm}$. The mean annual evaporation is $1510 \mathrm{~mm}$. The aridity index is 1.15 . Precipitation is low and unevenly distributed temporally and spatially. This area is a part of the typical semiarid hill and gully region of the Loess Plateau, with altitudes ranging from 1900 to $2250 \mathrm{~m}$.

The watershed area is $8.91 \mathrm{~km}^{2}$, which belongs to the hill and gully region of Loess Plateau. Gully density is $3.14 \mathrm{~km} \mathrm{~km}^{-2}$, and the ditch depth ranges from 30 to $50 \mathrm{~m}$. The soil are of the yellow loessial and saline soil types, and 


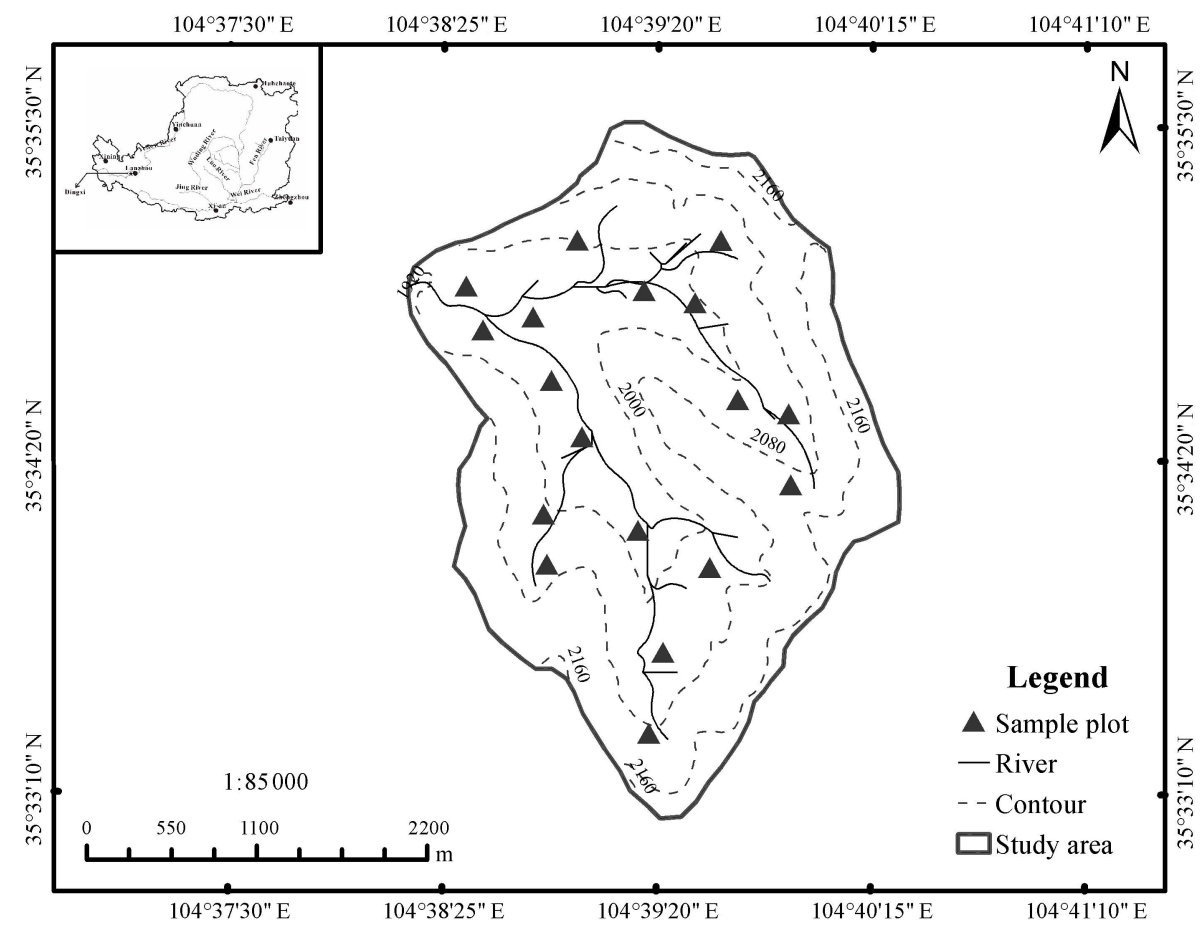

Figure 1. Location of the sampling sites in the study area.

the average thickness ranges from 40 to $60 \mathrm{~m}$. The density of the soil layer ranges from 1.1 to $1.4 \mathrm{~g} \mathrm{~cm}^{-3}$, average soil porosity is $55 \%$. Soil structure has a vertical joint, and the nature of soil is loose. The most dominant ecosystems in the Anjiagou River basin are grass and shrubland.

The study area has broken terrain and serious soil erosion, with an overall gully- and valley-filled landscape. Geological structure is the uplift zone between the eastern part of Qilian fold system and the western Qinling fold system, at an altitude of $1700-2580 \mathrm{~m}$, with the gully density of 3$5 \mathrm{~km} \mathrm{~km}^{-2}$, ditch slope of $5-10 \%$, and mountain slope of generally 20 to $50 \%$. The soil parent material is quaternary eolian loess, and the zonal soil mainly is yellow spongy soils, sierozem, which belongs to the typical semiarid loess hill and gully region. It has soft soil, homogeneous structure, thicker soil layers, good water performance and the widest distribution. The average thickness is $40-60 \mathrm{~m}$. Clay soil is between $33.12-42.17 \%$, organic matter content is between $0.37-1.34 \%$, soil bulk density is $1.17 \mathrm{~g} \mathrm{~cm}^{-3}$, wilting moisture content is $7.3 \%$ and the saturated moisture content is $21.9 \%$ at $0-20 \mathrm{~cm}$. The soil bulk density is 1.09 $1.36 \mathrm{~g} \mathrm{~cm}^{-3}$, and the porosity is $50-55 \%$ at the $2 \mathrm{~m}$ soil layer. The soil has vertical joint and strong collapsibility, so the soil erosion is easily happened, and the soil erosion modulus is $5000 \mathrm{t} \mathrm{km}^{-2} \mathrm{a}^{-1}$.

The vegetation type belongs to arid grassland vegetation type, with infrequent natural tree coverage. The grassland and shrubland ecosystems were the most extensive dominant ecosystems. Woodland area is minimal, most is open forest land. Areas with crown density of greater than 0.2 have only Caragana intermedia and Pinus tabulaeformis. The vegetation is sparse, and species diversity is relatively poor because of long-term influence by human activities. The artificial forest vegetation mainly consists of Caragana intermedia, Hippophae rhamnoides, Pinus tabulaeformis, Platycladus orientalis, Stipa bungeana, etc.

\subsection{Sample collection and field experiment}

The research was carried out in the Anjiagou River basin in the hill and gully region of Loess Plateau from May 2013 to October 2015. Samples of precipitation, soil, xylem and root were collected in the study area. The locations of the sampling sites are shown in Fig. 1. Precipitation was collected after each rainfall event. Precipitation was filtered and transferred to sealed glass vials prior to analysis. Plant xylem and root of Caragana korshinskii Kom. were collected at each sampling site, respectively. For sap water analysis, a plant twig ( 0.5 to $1 \mathrm{~cm}$ in diameter and about $5 \mathrm{~cm}$ in length) was cut from a main branch or trunk, cortical and phloem were peeled off. All samples were kept in $8 \mathrm{~mL}$ glass bottles and sealed with packaging tape to reduce evaporation. Five glass bottles were collected each plant at each sampling site. All samples were collected at least monthly. Altogether 27 samples sites and 396 samples were collected, and sealed with paraffin. The samples were taken back to the laboratory and preserved at $4^{\circ} \mathrm{C}$, and samples of soil, plant xylem, plant stem and leaf were refrigerated at $-20^{\circ} \mathrm{C}$ until analysis. 
Soil was sampled at $10 \mathrm{~cm}$ intervals for the first $40 \mathrm{~cm}$, $20 \mathrm{~cm}$ intervals from 40 to $100 \mathrm{~cm}$ and $30 \mathrm{~cm}$ intervals from 100 to $130 \mathrm{~cm}$. Maximum depths of sampling ranged up to $130 \mathrm{~cm}$ (plant root is rarely found below $100 \mathrm{~cm}$ in the study area). At each sampling site, soil moisture (volumetric soil water content) was obtained with time domain reflectometry (TDR) in the field manually at $0-10,10-20,20-30,30$ $40,40-60,60-80,80-100$ and $100-130 \mathrm{~cm}$. Soil moisture content was determined by oven drying simultaneously.

\subsection{Laboratory analysis}

Water was extracted from soil, xylem, root, stem and leaf by cryogenic vacuum distillation method, and the extracted water $(2$ to $10 \mathrm{~mL})$ was trapped at liquid nitrogen temperature. Vacuum distillation was considered a reliable and acceptable method. The moisture in the soil or plants under the condition of vacuum (vacuum below 60 mTorr), was heated to $105^{\circ}$ after evaporation. Water vapor of evaporation in $-50^{\circ}$ (liquid nitrogen) was collected with frozen water collecting pipe (top-down frozen, in order to increase the collecting rate), and the extraction precision was within $\delta \mathrm{D}$ and $\delta^{18}$ are \pm 3 and $\pm 0.3 \%$, respectively. Water samples were filtered through $0.2 \mu \mathrm{m}$ Millipore membrane for trace elements analyses. Isotopes $\delta^{18} \mathrm{O}$ and $\delta \mathrm{D}$ were measured in the Key Laboratory of Ecohydrology and River Basin Science of Cold and Arid Region Environmental and Engineering Institute, Chinese Academy of Sciences. $\delta^{18} \mathrm{O}$ of samples was analyzed by a Euro-PyrOH elemental analyzer at a temperature of $1300^{\circ} \mathrm{C}$, and $\delta \mathrm{D}$ was analyzed at a temperature of $1030^{\circ} \mathrm{C}$. At both temperatures the reaction products were analyzed on a GV Isoprime continuous-flow isotope ratio mass spectrometer. In order to eliminate the memory effect of online and continues flow, every sample was analyzed six times. The analytical precision of $\delta \mathrm{D}$ calculations was $\pm 1 \%$, and that of $\delta^{18} \mathrm{O} \pm 0.2 \%$. Isotopic concentration was expressed as $\delta$ per thousand $(\% \circ)$ relative to the Vienna Standard Mean Ocean Water, according to the follow equation:

$$
\begin{aligned}
& \delta^{18} \mathrm{O}(\% \circ)=\frac{\left({ }^{18} \mathrm{O} /{ }^{16} \mathrm{O}\right)_{\text {sample }}-\left({ }^{18} \mathrm{O} /{ }^{16} \mathrm{O}\right)_{\text {SMOW }}}{\left({ }^{18} \mathrm{O} /{ }^{16} \mathrm{O}\right)_{\text {SMOW }}} \times 1000, \\
& \delta \mathrm{D}(\% \circ)=\frac{(\mathrm{D} / \mathrm{H})_{\text {sample }}-(\mathrm{D} / \mathrm{H})_{\text {SMOW }}}{(\mathrm{D} / \mathrm{H})_{\text {SMOW }}} \times 1000 .
\end{aligned}
$$

\subsection{Statistical analysis}

When $n$ isotope is used to determine the proportional contributions of $i+1$ sources to a mixture, standard linear mixing models can be used to mathematically solve for the unique combination of source proportions that conserves mass balance for all $n$ isotopes (Phillips et al., 2013). In this study, the conservative elements $\mathrm{D}$ and ${ }^{18} \mathrm{O}$ are utilized to calculate mixing amounts of potential water source. The mixing model is used to calculate the contributions of each respective end member. The mixing model is described on the basis of the mass balance equation:

$$
\begin{aligned}
& \delta \mathrm{D}_{\mathrm{p}}=\sum_{i=1}^{n} f_{i} \delta \mathrm{D}_{i}, \\
& \delta^{18} \mathrm{O}_{\mathrm{p}}=\sum_{i=1}^{n} f_{i} \delta^{18} \mathrm{O}_{i}, \\
& I=\sum_{i=1}^{n} f_{i},
\end{aligned}
$$

where $\delta \mathrm{D}$ and $\delta^{18} \mathrm{O}$ are concentrations of the tracers; $I$ refers to potential water source; $\delta \mathrm{D}_{\mathrm{p}}$ and $\delta^{18} \mathrm{O}_{\mathrm{p}}$ refer to plant waters; $f_{i}$ is the fraction of each component contributing to plant water.

\section{Results}

\subsection{Isotopic composition of precipitation}

Yurtsever and Gat (1981) modified Craig's global water line, and made a more accurate global precipitation linear relationship between $\delta \mathrm{D}$ and $\delta^{18} \mathrm{O}$ of $\delta \mathrm{D}=8.17 \delta^{18} \mathrm{O}+10.56$, which is the global meteoric water line (GMWL). Figure 2 shows the relationship between mean $\delta^{18} \mathrm{O}$ and mean $\delta \mathrm{D}$ in precipitation, which is defined as the local meteoric water line (LMWL) with the equation $\delta \mathrm{D}=7.41 \delta^{18} \mathrm{O}+7.22$, with $R^{2}=0.95$. The $\delta^{18} \mathrm{O}$ and $\delta \mathrm{D}$ compositions of the precipitation in the Anjiagou River catchment are extremely variable, ranging from -118.36 to $-22.32 \%$ and from -16.35 to $-2.19 \%$, respectively. Thirty-four precipitation samples were collected from May 2013 to October 2015. There are significant differences in the composition of $\mathrm{D}$ and ${ }^{18} \mathrm{O}$ under different precipitation events. The difference reflects the extreme nature of the climate and the complexity of moisture sources in the arid region. Compared with GMWL, the slope and intercept of LMWL are lower than that of GMWL (Fig. 2), indicating that they are affected by the local climate and environment with less precipitation and lower humidity. When the slope is low, the implication is that precipitation is subject to evaporation. The Anjiagou River basin is located in the northwestern inland region, and it is difficult for the sea water vapor to reach directly. This indicates that the significant imbalance of isotope dynamic fractionation exists, which are strongly affected by strong solar radiation and evaporation in the local environment, leading to the enrichment in $\delta^{18} \mathrm{O}$ and $\delta \mathrm{D}$. Therefore, the slope of LMWL is low, and the intercept of LMWL decreases with the slope.

\subsection{The variations of $\delta \mathrm{D}$ and $\delta^{18} \mathrm{O}$ in soil water vertical profiles}

Stable isotope compositions of soil water are presented in Table 1 . The measured $\delta \mathrm{D}$ and $\delta^{18} \mathrm{O}$ of soil water range from -72.42 to $-37.05 \%$ and -11.74 to $-3.57 \%$, respectively. By comparing the isotopic composition of soil water with 
Table 1. Statistic characteristics of isotopic compositions for precipitation and soil water in the study area.

\begin{tabular}{|c|c|c|c|c|c|c|c|c|c|c|c|}
\hline \multirow[t]{2}{*}{ Type } & \multirow{2}{*}{$\begin{array}{r}\text { Depth } \\
(\mathrm{cm})\end{array}$} & \multicolumn{5}{|c|}{$\delta^{18} \mathrm{O}(\% \circ)$} & \multicolumn{5}{|c|}{$\delta \mathrm{D}(\% \circ)$} \\
\hline & & $n$ & Min & Max & Mean & SD & $n$ & Min & Max & Mean & SD \\
\hline Precipitation & & 34 & -16.35 & -2.19 & -8.26 & 1.9 & 34 & -118.36 & -22.32 & -55.15 & 5.7 \\
\hline \multirow{6}{*}{ Soil water } & 10 & 27 & -10.29 & -7.36 & -9.73 & 0.7 & 27 & -67.27 & -49.70 & -53.24 & 3.9 \\
\hline & 20 & 27 & -8.80 & -3.57 & -7.20 & 1.2 & 27 & -72.71 & -44.32 & -48.32 & 4.1 \\
\hline & 40 & 27 & -11.35 & -7.09 & -10.36 & 0.6 & 27 & -74.21 & -61.53 & -71.31 & 1.7 \\
\hline & 60 & 27 & -12.79 & -9.75 & -11.24 & 0.9 & 27 & -86.91 & -74.8 & -76.80 & 2.4 \\
\hline & 80 & 27 & -11.53 & -8.92 & -10.35 & 0.5 & 27 & -78.82 & -57.22 & -62.42 & 1.8 \\
\hline & 100 & 27 & -10.75 & -8.34 & -9.31 & 0.6 & 27 & -78.11 & -51.89 & -64.89 & 1.5 \\
\hline
\end{tabular}

that of precipitation, the isotope compositions of soil water in the unsaturated zone are relatively enriched. Therefore, it could be beneficial to identify the influence of various water bodies on different precipitation events. As Fig. 2 shows, isotope compositions of most soil waters are plotted in the bottom of the LMWL and are close to the LMWL. The variable trends of $\delta \mathrm{D}$ and $\delta^{18} \mathrm{O}$ values of soil water are similar to that of precipitation. There is a strong linear relationship $\left(R^{2}=0.96\right)$ for $\delta \mathrm{D}$ and $\delta^{18} \mathrm{O}$ between precipitation and soil water, which indicates that soil water is originally recharged by precipitation. The soil water is increasingly enriched in $\mathrm{D}$ and ${ }^{18} \mathrm{O}$, which are influenced by evaporation (Table 1). It has been reported that soil water is normally more enriched because precipitation enters the soil and mixes with antecedent soil water that has been modified by evaporation.

Vertical profiles of soil water $\delta \mathrm{D}$ and ${ }^{18} \mathrm{O}$ in the Anjiagou River basin are shown in Fig. 3. The surface layer $(0-20 \mathrm{~cm})$ showed larger variations and higher $\delta \mathrm{D}$ and ${ }^{18} \mathrm{O}$ values than the deeper layer. $\delta \mathrm{D}$ and ${ }^{18} \mathrm{O}$ values of soil water are greatest at the surface layer (Fig. 3, Table 1). $\delta \mathrm{D}$ and ${ }^{18} \mathrm{O}$ values of shallow soil water at $0-10 \mathrm{~cm}$ are -10.29 to $-7.36 \%$ ond -72.71 to $-35.45 \%$, respectively. The $\delta \mathrm{D}$ and ${ }^{18} \mathrm{O}$ values of shallower soil water at $10-20 \mathrm{~cm}$ are also high (ranging from -8.08 to $-3.57 \%$ and from -67.27 to $-49.70 \%$ o, respectively). The net effect of evaporation is the enrichment of heavy isotopes near the soil surface. Soil profiles (Fig. 3) show the increase in the $\mathrm{D}-{ }^{18} \mathrm{O}$ with soil depths from 0 to $20 \mathrm{~cm}$, suggesting the occurrence of evaporation. The large variation in isotope compositions of shallow depths $(0-20 \mathrm{~cm}$ depth) may be caused by the precipitation and evapotranspiration effect. The correlation of the isotopic composition between soil water and precipitation is weak. These have been reported by many other studies (Gazis and Feng, 2004; Robertson and Gazis, 2006).

The $\delta^{18} \mathrm{O}$ and $\delta \mathrm{D}$ compositions of soil water at $40 \mathrm{~cm}$ depths range from -11.35 to $-7.09 \%$ and -74.21 to $-54.06 \%$, respectively. Soil water from 20 to $40 \mathrm{~cm}$ depths is easily influenced by precipitation infiltration and evapotranspiration, which leads to the extremely variable $\delta \mathrm{D}$ and

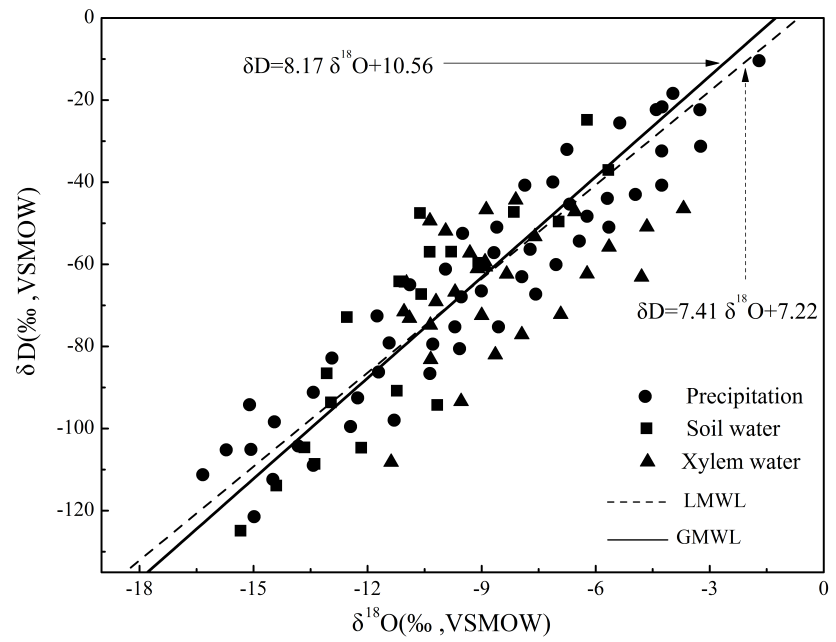

Figure 2. Plot of $\delta \mathrm{D}$ vs. $\delta^{18} \mathrm{O}$ for the various samples in the study area.

$\delta^{18} \mathrm{O}$ values of soil water (Fig. 3). The impact of precipitation on soil water becomes weaker with increasing depths. The isotopic composition of soil water is strongly enriched in $\delta \mathrm{D}$ and $\delta^{18} \mathrm{O}$ due to less precipitation and evaporation in the study area. The $\delta \mathrm{D}$ and $\delta^{18} \mathrm{O}$ decrease exponentially with the increasing depths, and the variation trends are larger. Previous studies have also shown that evaporation decreases with the increasing soil depth, and its influence is generally within tens of centimeters. $\delta \mathrm{D}$ and ${ }^{18} \mathrm{O}$ values declined with depth to $60 \mathrm{~cm}$ but remained constant at deeper depths. When it reaches $60 \mathrm{~cm}$ depth, the variation trend tends to be stationary. The $\delta^{18} \mathrm{O}$ and $\delta \mathrm{D}$ compositions of soil water at $60 \mathrm{~cm}$ depths ranged from -12.79 to $-9.75 \%$ oand from -96.91 to $-57.27 \%$, respectively. There is an abrupt peak value in the plant root zone. The isotopic fluctuations quickly disappear due to the dispersive effects of the deep root system.

However, the values of $\delta \mathrm{D}$ and $\delta^{18} \mathrm{O}$ gradually decrease from 60 to $80 \mathrm{~cm}$ because the recharge of precipitation decreases, and the influence of antecedent isotope value of soil water increases. As Fig. 3 shows, D and ${ }^{18} \mathrm{O}$ values of soil water at depths of $80 \mathrm{~cm}$ range from -11.53 to $-8.92 \%$ and 

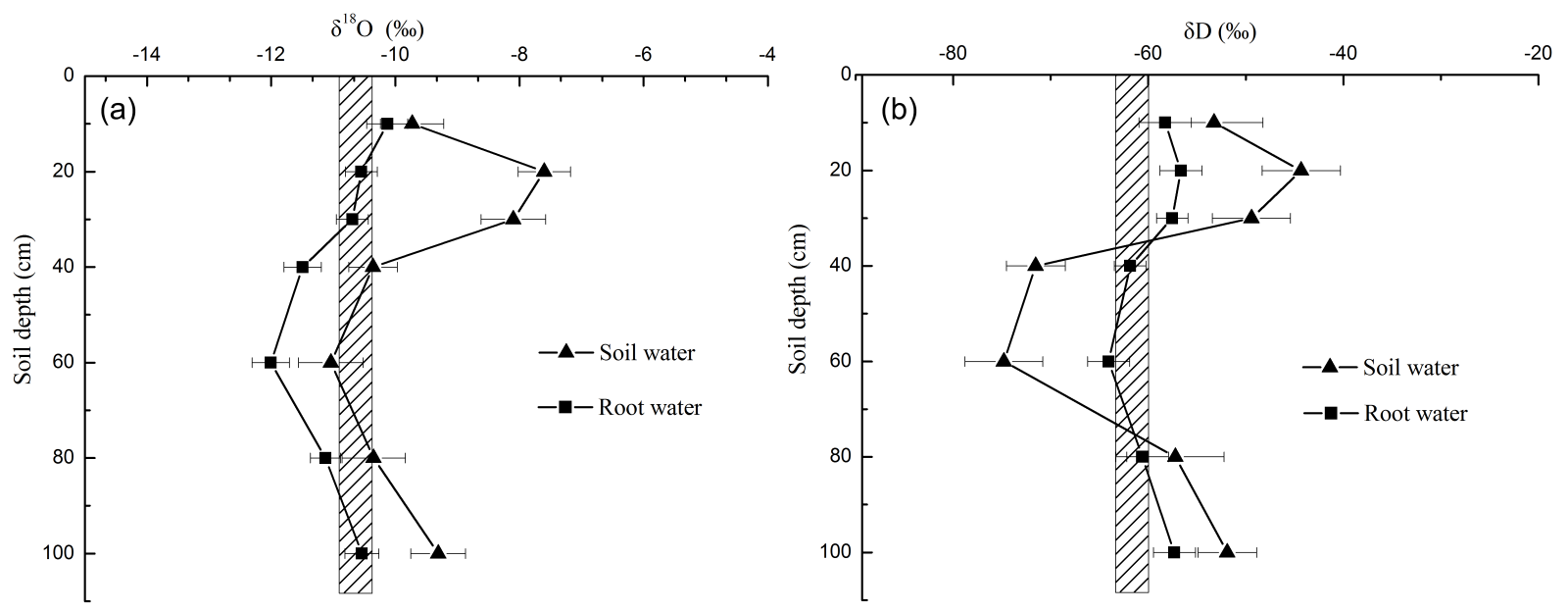

Figure 3. Isotope profiles of $\delta^{18} \mathrm{O}$ and $\delta \mathrm{D}$ (piston-type flow) in soil water and xylem water. Values are mean \pm 1 standard deviation $(n=27)$.

-78.82 to $-62.80 \%$, respectively. Compared with the large variation in the $\delta \mathrm{D}$ and $\delta^{18} \mathrm{O}$ of surface soil water, soil water deeper than $80 \mathrm{~cm}$ is almost constant. The low value zone is at $100 \mathrm{~cm}$ in the isotopic profiles of soil water, which is the deepest layer that is recharged by precipitation. Variations of $\delta^{18} \mathrm{O}$ and $\delta \mathrm{D}$ of soil water in the deep layer are non-significant. Evaporation is larger than precipitation in the study area. Precipitation is difficult to infiltrate to $80 \mathrm{~cm}$ depth in the shrubland ecosystems, except in the high flow years. Therefore, it is difficult to cause the isotope fractionation of soil water blow $80 \mathrm{~cm}$.

\subsection{Variability in soil moisture content}

Values of soil moisture obtained by TDR in the Anjiagou River basin are shown in Fig. 5. The variation of soil moisture content in the shallow soil layer $(0-40 \mathrm{~cm})$ is extremely large, ranging from 5.94 to $17.51 \%$, which belongs to the highly variable layer. The variation of soil moisture content at the $40-60 \mathrm{~cm}$ soil depth is relatively small, which belongs to the less active layer. The variation of soil moisture content is relatively stable at $60-100 \mathrm{~cm}$ soil depth, ranging from 17.78 to $29.47 \%$, which belongs to the relatively stable layer. Soil water content also exhibits depth variation. Variability of water content is larger in the surface horizons more than $40 \mathrm{~cm}$ depth in the soil profile. The shallow soil layers are impacted by evaporation and precipitation recharge more than the deeper soil layer. Therefore, the high evapotranspiration rate and precipitation recharge are the main factors controlling soil moisture, especially at the surface horizon.

As the soil moisture profile shows (Fig. 4), soil moisture content is low in the shallow layer $(0-20 \mathrm{~cm})$ and relatively high at the active layer $(40-60 \mathrm{~cm})$, and then tends to be stable. Figure 4 shows that soil moisture content is different in different sample sites, but soil moisture content is low under $60 \mathrm{~cm}$ soil depths in all the sample sites. Soil moisture con- tent generally increases with the increase of soil depth in the variable greatly layer. Soil moisture content decreases with the increase of soil depth in the active layer, and then tends to be stable.

As Fig. 4 shows, water content increases and soil water $\delta^{18} \mathrm{O}-\mathrm{D}$ values increase in the shallow layer $(0-40 \mathrm{~cm})$, which are impacted by evapotranspiration. This is the dominant process for most of the sites. Mean values of the soil moisture content increase with depth in the soil profile (40$60 \mathrm{~cm}$ depth), while soil water $\delta^{18} \mathrm{O}-\mathrm{D}$ values decrease with depth, where it mixes with antecedent moisture. Low water content and more positive ${ }^{18} \mathrm{O}-\mathrm{D}$ values (Fig. 4) occur at the deep soil layer (below $60 \mathrm{~cm}$ depth), which is impacted by recharge. Single precipitation events cannot easily infiltrate deeper than $80 \mathrm{~cm}$, when drought lasts for a long time, especially when soil water content is lower than $20 \%$. Extremely high values of soil water content at the depth of $60 \mathrm{~cm}$ are observed in the Anjiagou River basin. The higher water content and more negative $\delta^{18} \mathrm{O}$ values are observed in the active layer (40-60 cm; Fig. 4). The variability of water content and the ${ }^{18} \mathrm{O}-\mathrm{D}$ values are relatively larger for the surface horizons than deeper in the soil profile. The profile of soil moisture content is highly responsive to evaporation and precipitation. The average water content and soil water $\delta^{18} \mathrm{O}-\mathrm{D}$ values are representative of the trends found in most of the sample sites.

\section{Discussion}

\subsection{The migration process of soil water in the unsaturated zone}

Precipitation infiltration and evapotranspiration in the vertical direction are the main processes of the water cycle, playing an important role in the transformation process of the water cycle in the unsaturated zone. Different migration mecha- 

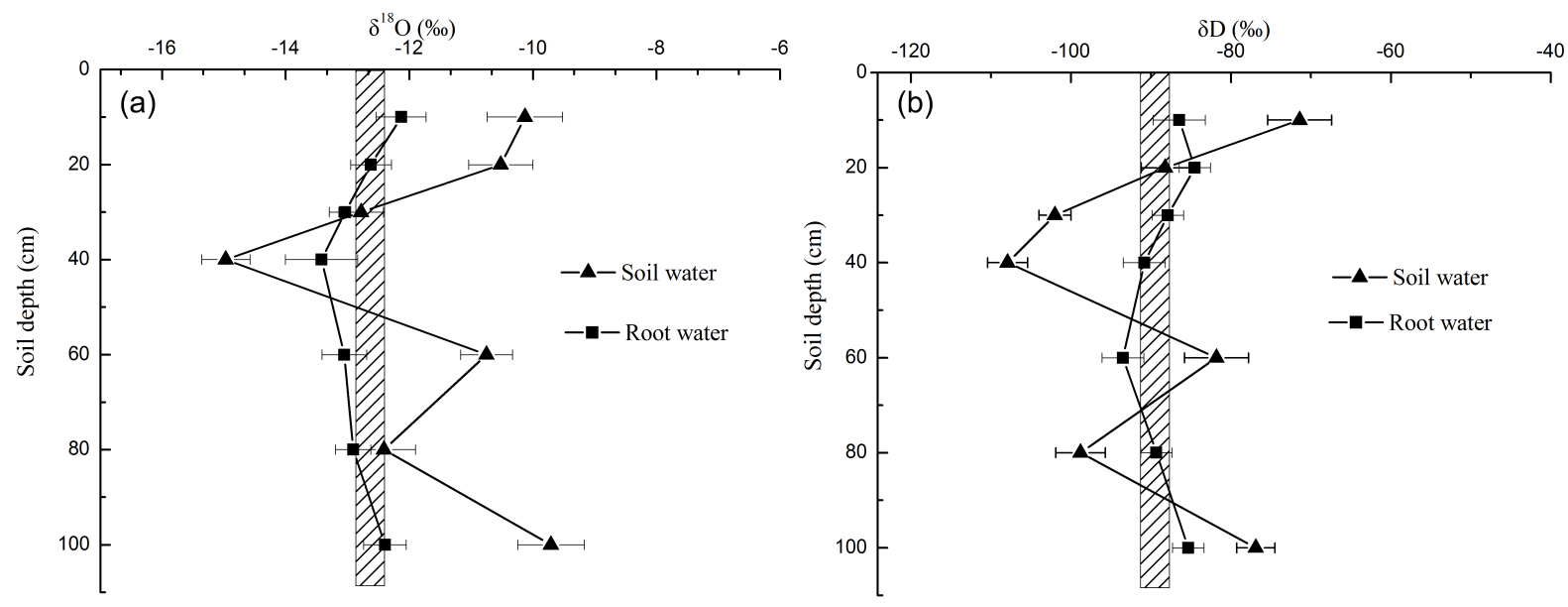

Figure 4. Isotope profiles of $\delta^{18} \mathrm{O}$ and $\delta \mathrm{D}$ (preferential flow) in soil water and xylem water. Values are mean \pm 1 standard deviation $(n=27)$.

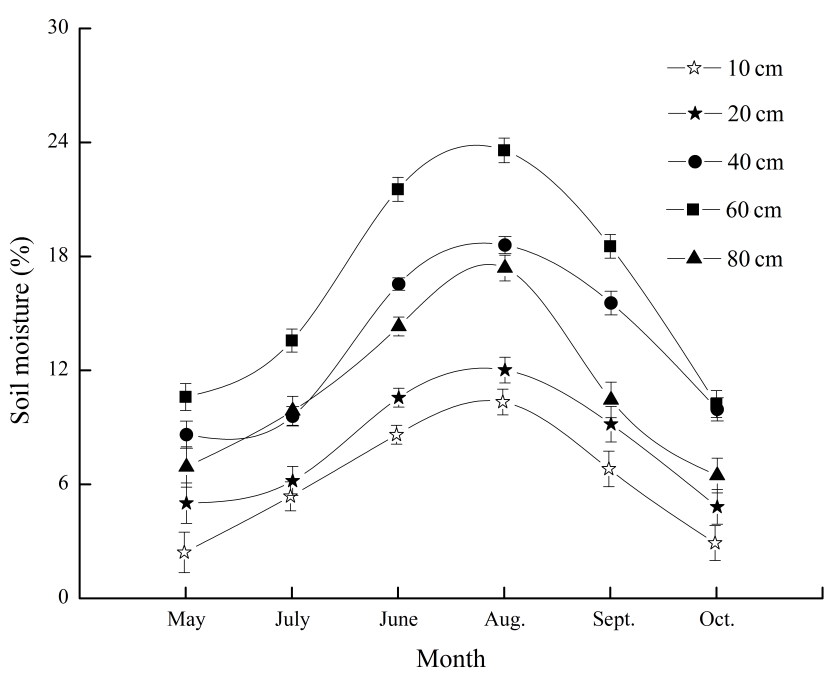

Figure 5. The variation of soil moisture content at different soil depths.

nisms of soil water result in different isotopic profiles. Therefore, isotope $\delta \mathrm{D}$ and $\delta^{18} \mathrm{O}$ of soil water and precipitation can be obtained to identify soil water migration processes such as infiltration, evaporation, transpiration and percolation through the soil waters at different depths. These different isotopic profiles may occur as a result of several processes, including evaporation, change in isotopic composition of precipitation and mixing of new and old water. While evaporation is widely recognized, we believe that mixing is also an important factor for controlling the isotopic composition of soil water at these sites. This is possibly caused by the infiltration of summer rainwater through the soil layer. Generally, there are two major infiltration mechanisms (pistontype flow and preferential flow) that can be identified by comparing the isotope compositions of precipitation and soil water.

\subsubsection{Evidence for piston-type flow}

The $\delta \mathrm{D}$ and $\delta^{18} \mathrm{O}$ content of soil water at different depths are shown in Fig. 4. By comparing the isotopic compositions of precipitation and soil water, the mechanisms of soil water movement can be identified. AT most of the sampling sites in the Anjiagou River basin (except at sites on 20 July 2014 and 24 September 2014), the isotopic composition of soil water in shallow layer are enriched in $\mathrm{D}$ and ${ }^{18} \mathrm{O}$ due to evaporation. The isotopic composition of soil water changes with depth in the soil profile, especially after continuous precipitation between 18 and 20 August 2014. Precipitation infiltrated and completely mixed with free water. The vertical trend in the $\delta \mathrm{D}$ and $\delta^{18} \mathrm{O}$ profiles of soil water is simple. There is an abrupt peak value in the isotopic profiles, which suggests that the older water is pushed downward by the new water and infiltrates to the deep soil. That is, while some soil water remains stationary, the mobile soil water successively displaces pre-existing mobile soil water, pushing it downward. Pistontype flow after an isotopic distinct rainfall event results in an abrupt "isotopic front" within the soil (Gehrels et al., 1998; Song et al., 2009). The evidence for mixing is that abrupt changes in the soil water $\delta \mathrm{D}$ and $\delta^{18} \mathrm{O}$ with depth in the soil profile indicates that piston flow has occurred. A relatively flat pattern is observed, slightly enriched in accordance with precipitation. $\delta \mathrm{D}$ and $\delta^{18} \mathrm{O}$ declined with depth to $60 \mathrm{~cm}$ but remained constant at deeper depths. The older soil water is pushed downward by newer rainwater. Precipitation infiltration exhibits piston infiltration characteristics (Zimmerman et al., 1967).

\subsubsection{Evidence for preferential flow}

At the sample sites on 20 July 2014 and 24 September 2014, the vertical trend of $\delta \mathrm{D}$ and $\delta^{18} \mathrm{O}$ in the soil profile indicates a uniform infiltration process (Fig. 5). There are two abrupt peak values in the isotopic vertical profiles of soil 
water. The soil water at depths between 20 and $40 \mathrm{~cm}$ decreases quickly, caused by the strong transpiration effect of plants roots. Abrupt change occurred at $20-40 \mathrm{~cm}$ depth of the isotopic profile where the soil water moisture increased quickly (ranging from -14.97 to $-12.78 \%$ and -107.93 to $-101.21 \%$, respectively). There are two continuous rainfall events on 20 July 2014 and 24 September 2014 (the rainfall event on 20 July 2014, with precipitation of $25 \mathrm{~mm}$, lasted for 3 days. The rainfall event on 24 September 2014, with the precipitation of $16 \mathrm{~mm}$, lasted for 2 days), which infiltrated uniformly into deep depths, as shown by the reducing $\delta \mathrm{D}$ and $\delta^{18} \mathrm{O}$ values with time after the precipitation (Fig. 4). The data do not show the obvious correlation with depth at the 20 July 2014 and 24 September 2014 samples sites in the Anjiagou River basin (Fig. 4). This is mainly caused by the mixture effect occurred during the process of infiltration. That is to say, the newer water, which did not replace the old water totally during the process of infiltration, mixed with the old water stored in the soil.

The second peak of $\delta^{18} \mathrm{O}$ and $\delta \mathrm{D}$ values of soil water is at the depth of $80 \mathrm{~cm}$ (ranging from -12.41 to $-10.75 \%$ ond -98.87 to $-82.77 \%$, respectively), caused most likely by macropore flow. The non-existence of a significant difference between the isotopic content of precipitation and soil water suggests that the infiltrating summer precipitation passes the root zone quickly and contributes to the soil water recharge. The deep soil water is recharged by precipitation in the form of preferential flow, which passes the soil porosity and quickly reaches the deep layer, and does not mix with older water. Variations of $\delta^{18} \mathrm{O}$ and $\delta \mathrm{D}$ of deep soil water are only due to mixing, rarely from evaporation. A number of studies documenting tracer movement in the soil column have pointed out the existence of preferential fluid flow, which can be caused by cracks (in dried soil), macropores (Beven and Germann, 1982), plant roots, earthworm burrows, etc. (Vincent et al., 2001; Bronswijk, 1991). However, the preferred flow is rarely found in the Loess Plateau, except from macropores, caused by plant root system or animal invasion, etc. The deep soil water is quickly recharged by precipitation in the form of preferential flow through observing the excavated soil profile. The macropores can be found in the $100-200 \mathrm{~cm}$ soil layer in the study area, which are created by plant roots. The cracks in the Loess Plateau can also provide an important path for preferential flow. This is supported by the variations of soil water content. The soil water content at $80 \mathrm{~cm}$ depth increases quickly. The soil water content ranges from 34.5 to $36.8 \%$. At corresponding depths of the isotope profile, the isotope values are relatively depleted. Significant soil water content increase in the deep soil is similar to variability of isotopic composition of soil water. The isotope profile can provide some evidence for preferential flow.

\subsection{Origin and contribution of each potential water source to plants}

\subsubsection{Plant water sources}

Zimmermann et al. (1967) studied the effect of transpiration with an experiment in which the root water uptake of various plant species is monitored, and no fractionation is found. Allison and Barnes (1985) tested a much greater fraction of root water uptake and found no conclusive proof of fractionation by root water uptake. Isotope fractionation is not caused when soil water is taken up by plant roots. By comparing the $\delta \mathrm{D}$ and $\delta^{18} \mathrm{O}$ of plant water and each water sources, the water origin and contribution of each component for xylem could be identified.

The isotopic composition of the soil layer is similar to the xylem water, confirmed by comparing $\delta \mathrm{D}$ and $\delta^{18} \mathrm{O}$ of xylem water and soil water, which reflect the signatures of soil at the depth of soil water uptake by plants. All the soil and xylem samples are taken simultaneously in the Anjiagou River basin. The isotopes of $\delta \mathrm{D}$ and $\delta^{18} \mathrm{O}$ are conservative and do not react with clay minerals and other soil materials. During the process of transpiration, the soil water content changes, but the isotopic composition of soil water remains constant. The isotopic composition of plant xylem water is a mixture of soil water at different soil depths. The isotopic composition of xylem water, soil water and precipitation in the Anjiagou River basin is analyzed. The isotopic composition of plant xylem water is a mixture of soil water at different soil depths. Comparing the signatures $\delta \mathrm{D}$ and $\delta^{18} \mathrm{O}$ of both soil water and xylem water with a simple graphical interference approach indicates a distinct difference between both isotopes. Graphical "best match" approach is suitable to illustrate water uptake depth as plants often withdraw water from more than one distinct soil depth. The $\delta \mathrm{D}$ and $\delta^{18} \mathrm{O}$ in xylem water ranged from -11.64 to $-7.95 \%$ and from -81.62 to $-55.21 \%$, respectively (Fig. 6, Table 2). Plant xylem water $\delta \mathrm{D}$ and $\delta^{18} \mathrm{O}$ for both species is similar to that of soil water at $40-60 \mathrm{~cm}$ depth (Fig. 6). It indicates that soil water at the $40-60 \mathrm{~cm}$ depth is mainly used by Caragana korshinskii Kom.

\subsubsection{The contribution of each potential water source to plants water}

Hooper (2003) and Christophersen and Hooper (1992) introduced the end-member mixing analysis (EMMA), which is an often used method for analyzing possible source area contributions to flow. Multiple-source mixing models (Parnell et al., 2010; Phillips et al., 2013) account for water uptake from more than one discrete soil layer and weigh the importance of certain layers for water uptake by incorporating soil water potentials into the calculation. In this study, the mixing model is used to identify potential source areas and mixing processes, and to quantify the contribution of each end mem- 
Table 2. Statistic characteristics of isotopic compositions for root water and xylem water in the study area.

\begin{tabular}{|c|c|c|c|c|c|c|c|c|c|c|c|}
\hline \multirow[t]{2}{*}{ Type } & \multirow{2}{*}{$\begin{array}{l}\text { Depth } \\
(\mathrm{cm})\end{array}$} & \multicolumn{5}{|c|}{$\delta^{18} \mathrm{O}(\% \circ)$} & \multicolumn{5}{|c|}{$\delta \mathrm{D}(\% o)$} \\
\hline & & $n$ & Min & $\operatorname{Max}$ & Mean & SD & $n$ & Min & Max & Mean & SD \\
\hline Xylem water & & 27 & -11.64 & -7.95 & -10.61 & 0.66 & 27 & -81.62 & -55.21 & -69.94 & 4.9 \\
\hline \multirow{6}{*}{ Root water } & 10 & 27 & -14.21 & -5.12 & -8.34 & 0.64 & 27 & -62.39 & -52.99 & -62.37 & 5.4 \\
\hline & 20 & 27 & -10.27 & -5.97 & -9.21 & 1.5 & 27 & -56.21 & -44.18 & -59.38 & 3.3 \\
\hline & 40 & 27 & -11.79 & -6.91 & -10.1 & 0.89 & 27 & -73.20 & -61.56 & -67.05 & 4.2 \\
\hline & 60 & 27 & -12.47 & -8.08 & -10.6 & 0.77 & 27 & -83.49 & -65.95 & -73.14 & 2.9 \\
\hline & 80 & 27 & -11.99 & -8.92 & -9.7 & 0.81 & 27 & -81.18 & -57.72 & -66.75 & 1.7 \\
\hline & 100 & 27 & -9.80 & -7.3 & -8.9 & 0.64 & 27 & -70.57 & -59.27 & -60.62 & 2.5 \\
\hline
\end{tabular}

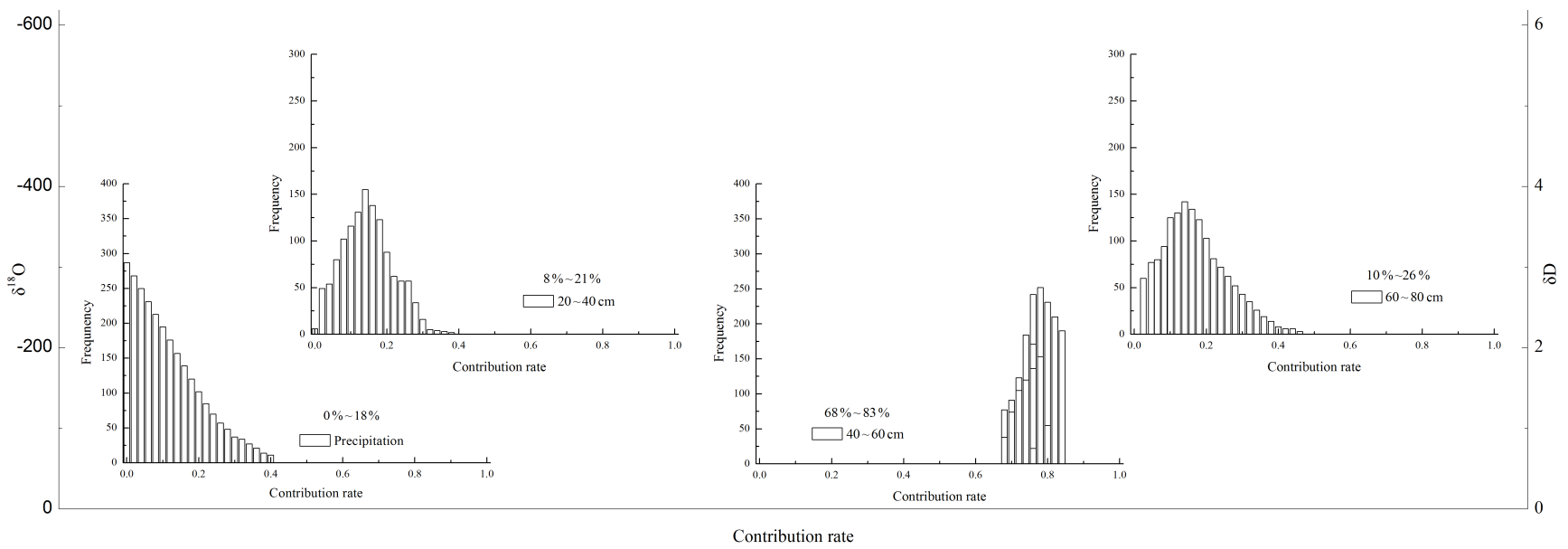

Figure 6. The contributions of each potential water source to plants.

ber using mixture fractions. The conservative elements $\delta \mathrm{D}$ and $\delta^{18} \mathrm{O}$ are utilized as tracers to calculate mixing amounts.

It is more likely that plant xylem water is a mixture of soil water from several soil depths. Multiple-source massbalance mixing models of proportional contributions (\%) of plant xylem water (Parnell et al., 2010) is used to evaluate the contributions of each potential water source (Fig. 6). The results show that soil water from the surface horizons (20$40 \mathrm{~cm}$ ) comprised $8-21 \%$ of plant xylem water, while soil water at $40-60 \mathrm{~cm}$ soil depth comprised the largest portion of plant xylem water (ranging from 68 to $83 \%$ ). Soil water below $60 \mathrm{~cm}$ depth comprised $10-26 \%$ of plant xylem water and only $0-18 \%$ comes directly from precipitation. Water source is dominated by soil water at a depth of $40-60 \mathrm{~cm}$.

\section{Conclusions}

The following conclusions can be drawn from the present study:

1. $\delta^{18} \mathrm{O}$ and $\delta \mathrm{D}$ enrichment in the shallow $(<20 \mathrm{~cm}$ depth) soil water, observed in most soil profiles, is due to evaporation. The isotopic composition of xylem water is close to that of soil water at a depth of $40-60 \mathrm{~cm}$. These values reflect soil water signatures associated with shrubland uptake at a depth of $40-60 \mathrm{~cm}$.

2. A sharp isotopic front at approximately $40 \mathrm{~cm}$ depth observed shortly after an isotopic distinct rainfall event suggests that infiltration into soil occurred as pistontype flow with newer water pushing older water downward in the soil profile. Soil waters are recharged from precipitation. The soil water migration is dominated by piston-type flow in the study area and rarely preferential flow, except where there are macrospores in the Loess Plateau, caused by plant root or animal invasion, etc. Water migration exhibited a transformation pathway from precipitation to soil water to plant water.

3. Soil water from the surface horizons $(20-40 \mathrm{~cm}) \mathrm{com}-$ prised 8-21\% of plant xylem water, while soil water at $40-60 \mathrm{~cm}$ soil depth was the is the largest component of plant xylem water (ranging from 68 to $83 \%$ ). Soil water below $60 \mathrm{~cm}$ depth comprised $10-26 \%$ of plant xylem water and only $0-18 \%$ comes directly from precipitation. Water source is dominated by soil water at depth of $40-60 \mathrm{~cm}$. 
Competing interests. The authors declare that they have no conflict of interest.

Acknowledgements. This research is supported by National Natural Science Foundation of China (41390464;41201043), and China Postdoctoral Science Foundation Funded Project (2014M550095). The authors are grateful to the experimental research station staff and all participants in the field for their contributions to the progress of this study. We also express our appreciation to the anonymous reviewers of the manuscript.

Edited by: B. $\mathrm{Hu}$

Reviewed by: L. Bing and four anonymous referees

\section{References}

Allison, G. B. and Barnes, C. J.: Estimation of evaporation from the normally "dry" Lake Frome in South Australia, J. Hydrol., 78, 229-242, 1985.

Arny, E. S., Hans, C. S., Thorsteinn, J., and Sigfus, J. J.: Monitoring the water vapor isotopic composition in the temperate North Atlantic, J. Geophys. Res.-Abstr., 15, 2013-5376, 2013.

Beven, K. and Germann, P.: Macropores and water flow in soils, Water Resour. Res., 18, 1311-1325, 1982.

Bhatia, M. P., Das, S. B., and Kujawinski, E. B.: Seasonal evolution of water contributions to discharge from a Greenland outlet glacier: insight from a new isotope-mixing model, J. Glaciol., 57, 929-941, 2011.

Bose, T., Sengupta, S., Chakraborty, S., and Borgaonkar, H.: Reconstruction of soil water oxygen isotope values from tree ring cellulose and its implications for paleoclimate studies, Quatern. Int., 425, 387-398, 2016.

Brodersen, C., Pohl, S., Lindenlaub, M., Leibundgut, C., and Wilpert, K. V.: Influence of vegetation structure on isotope content of throughfall and soil water, Hydrol. Process., 14, 14391448, 2015.

Bronswijk, J. J. B.: Magnitude, modelling and significance of swelling and shrinkage processes in clay soils, PhD Thesis, 1991.

Busari, M. A., Salako, F. K., Tuniz, C., and Zuppi, G. M.: Estimation of soil water evaporative loss after tillage operation using the stable isotope technique, Int. Agrophys., 27, 257-264, 2013.

Caley, T. and Roche, D. M.: $\delta^{18} \mathrm{O}$ water isotope in the iLOVECLIM model (version 1.0) - Part 3: A palaeo-perspective based on present-day data-model comparison for oxygen stable isotopes in carbonates, Geosci. Model Dev., 6, 1505-1516, doi:10.5194/gmd-6-1505-2013, 2013.

Carucci, V., Petitta, M., and Aravena, R.: Interaction between shallow and deep aquifers in the Tivoli Plain enhanced by groundwater extraction: A multi-isotope approach and geochemical modeling, Appl. Geochem., 27, 266-280, 2012.

Catherne, C. G., Alan, F. M., and Katharine, J. M.: Hydrological processes and chemical characteristics of low-alpine patterned wetlands, south-central New Zealand, J. Hydrol., 385, 105-119, 2010.

Christophersen, N. and Hooper, R. P.: Multivariate analysis of stream water chemical data: the use of components analysis for the end-member mixing problem, Water Resour. Res., 28, 99107, 1992.

Ferretti, D. F., Pendall, E., Morgan, J. A., Nelson, J. A., LeCain, D., and Mosier, A. R.: Partitioning evapotranspiration fluxes from Colorado grassland using stable isotopes: Seasonal variations and ecosystem implications of elevated atmospheric $\mathrm{CO}_{2}$, Plant Soil, 254, 291-303, 2003.

Gazis, C. and Feng, X.: A stable isotope study of soil water: evidence for mixing and preferential flow paths, Geoderma, 119, 97-111, 2004.

Gehrels, J. C., Peeters, E. M., De Vries, J. J., and Dekkers, M.: The mechanism of soil water movement as inferred from ${ }^{18} \mathrm{O}$ stable isotope studies, Hydrolog. Sci. J., 43, 579-594, 1998.

Gierke, C., Newton, B. T., and Phillips, F. M.: Soil-water dynamics and tree water uptake in the Sacramento Mountains of New Mexico: a stable isotope study, Hydrogeol. J., 24, 1-14, 2016.

Haverd, V., Cuntz, M., and Griffith, D.: Measured deuterium in water vapour concentration does not improve the constraint on the partitioning of evapotranspiration, using a soil vegetation atmosphere transfer model, Agr. Forest Meteorol., 151, 645-654, 2011.

Heathman, G. C., Cosh, M. H., Merwade, V., and Han, E.: Multiscale temporal stability analysis of surface and subsurface soil moisture within the Upper Cedar Creek Watershed, Indiana, Catena, 95, 91-103, 2012.

Hooper, R. P.: Diagnostic tools for mixing models of stream water chemistry, Water Resour. Res., 39, 249-256, 2003.

Kevin, W. T., Brent, B. W., and Thomas, W. D. E.: Characterizing the role of hydrological processes on lake water balances in the old Crow Flats, Yukon Territory, using water isotope tracers, J. Hydrol., 386, 103-117, 2010.

Kidron, G. J. and Gutschick, V. P.: Soil moisture correlates with shrub-grass association in the Chihuahuan Desert, Catena, 107, 71-79, 2013.

Koeniger, P., Gaj, M., Beyer, M., and Himmelsbach, T.: Review on soil water isotope-based groundwater recharge estimations, Hydrol. Process., 30, 2817-2834, 2016.

Lin, Y. and Horita, J.: An experimental study on isotope fractionation in a mesoporous silica-water system with implications for vadose-zone hydrology, Geochim. Cosmochim. Ac., 184, 257271, 2016.

Liu, H., Tian, F., Hu, H. C., Hu, H. P., and Sivapalan, M.: Soil moisture controls on patterns of grass green-up in Inner Mongolia: an index based approach, Hydrol. Earth Syst. Sci., 17, 805-815, doi:10.5194/hess-17-805-2013, 2013.

Liu, Y., Xu, Z., Duffy, R., Chen, W., An, S., Liu, S., and Liu, F.: Analyzing relationships among water uptake patterns, rootlet biomass distribution and soil water content profile in a subalpine shrubland using water isotopes, Eur. J. Soil Biol., 47, 380-386, 2011.

Lu, N., Chen, S. P., Wilske, B., Sun, G., and Chen, J.: Evapotranspiration and soil water relationships in a range of disturbed and undisturbed ecosystems in the semi-arid Inner Mongolia, China, J. Plant Ecol., 4, 49-60, 2011.

Luo, G. J., Kiese, R., Wolf, B., and Butterbach-Bahl, K.: Effects of soil temperature and moisture on methane uptake and nitrous oxide emissions across three different ecosystem types, Biogeosciences, 10, 3205-3219, doi:10.5194/bg-10-3205-2013, 2013. 
Manzoni, S., Giulia, V., Gabriel, K., Sari, P., and Robert, B. J.: Hydraulic limits on maximum plant transpiration and the emergence of the safety-efficiency trade-off, New Phytol., 198, 169-178, 2013.

Mathieu, R. and Bariac, T.: An isotopic study $\left({ }^{2} \mathrm{H}\right.$ and $\left.{ }^{18} \mathrm{O}\right)$ of water movements in clayey soils under a semiarid climate, Water Resour. Res., 32, 779-789, 1996.

Maurya, A. S., Shah, M., and Deshpande, R. D.: Hydrograph separation and precipitation source identification using stable water isotopes and conductivity: River Ganga at Himalayan foothills, Hydrol. Process., 25, 1521-1530, 2011.

McInerney, F. A., Helliker, B. R., and Freeman, K. H.: Hydrogen isotope ratios of leaf wax nalkanes in grasses are insensitive to transpiration, Geochim. Cosmochim. Ac., 75, 541-554, 2011.

Návar, J.: Stemflow variation in Mexico's northeastern forest communities: Its contribution to soil moisture content and aquifer recharge, J. Hydrol., 408, 35-42, 2011.

Ohlanders, N., Rodriguez, M., and McPhee, J.: Stable water isotope variation in a Central Andean watershed dominated by glacier and snowmelt, Hydrol. Earth Syst. Sci., 17, 1035-1050, doi:10.5194/hess-17-1035-2013, 2013.

Orlowski, N., Pratt, D. L., and Mcdonnell, J. J.: Intercomparison of soil pore water extraction methods for stable isotope analysis, Hydrol. Process., 30, 3434-3449, 2016 a.

Orlowski, N., Breuer, L., and McDonnell, J. J.: Critical issues with cryogenic extraction of soil water for stable isotope analysis, Ecohydrology, 9, 3-10, 2016b.

Parnell, A. C., Inger, R., Bearhop, S., and Jackson, A. L.: Source Partitioning Using Stable Isotopes: Coping with Too Much Variation, Plos One, 5, e9672, doi:10.1371/journal.pone.0009672, 2010.

Phillips, S. J., Anderson, R. P., and Schapire, R. E.: Maximum entropy modeling of species geographic distribution, Ecol. Model., 19, 231-259, 2013.

Robertson, J. A. and Gazis, C. A.: An oxygen isotope study of seasonal trends in soil water fluxes at two sites along a climate gradient in Washington state (USA), J. Hydrol., 328, 375-387, 2006.

Singh, B. P.: Isotopic composition of water in precipitation in a region or place, J. Appl. Radiat. Isot., 75, 22-25, 2013.
Song, X. F., Wang, S. Q., Xiao, G. Q., Wang, Z. M., Liu, X., and Wang, P.: A study of soil water movement combining soil water potential with stable isotopes at two sites of shallow groundwater areas in the North China Plain, Hydrol. Process., 23, 1376-1388, 2009.

Stumpp, C., Maloszewski, P., and Stichler, W.: Environmental isotope $\left(\delta^{18} \mathrm{O}\right)$ and hydrological data to assess water flow in unsaturated soils planted with different crops, J. Hydrol., 36-, 198-208, 2009.

Vincent, M., Didon-Lescot, J. F., and Couren, M.: Investigation of the hydrological processes using chemical and isotopic tracers in a small Mediterranean forested catchment during autumn recharge, J. Hydrol., 247, 215-229, 2001.

William, T. P. and Eric, E. S.: The influence of spatial patterns of soil moisture on the grass and shrub responses to a summer rainstorm in a Desert ecotone, Ecosystems, 13, 511-525, 2010.

Yang, Y. G., Xiao, H. L., Wei, Y. P., and Zou, S. B.: Hydrologic processes in the different landscape zones in the alpine cold region during the melting period, J. Hydrol., 409, 149-156, 2011.

Yang, Y. G., Xiao, H. L., Wei, Y. P., and Zou, S. B.: Hydrochemical and hydrological processes in the different landscape zones of alpine cold region in China, Environ. Earth Sci., 65, 609-620, 2012a.

Yang, Y. G., Xiao, H. L., Wei, Y. P.. and Zou, S. B.: Hydrological processes in the different landscape zones of alpine cold regions in the wet season, combining isotopic and hydrochemical tracers, Hydrol. Process., 25, 1457-1466, 2012b.

Yang, Y. G., Xiao, H. L., and Zou, S. B.: Hydrogen and oxygen isotopic records in monthly scales variations of hydrological characteristics in the different landscape zones, J. Hydrol., 499, 124 131, 2013.

Yurtsever, Y. and Gat, J. R.: Atmospheric waters, in: Stable Isotope Hydrology: Deuterium and Oxygen-18 in the Water Cycle, Technical Report Series, IAEA, Vienna, 103-142, 1981.

Zhao, L. J., Wang, L. X., and Xiao, H. L.: The effects of short-term rainfall variability on leaf isotopic traits of desert plants in sandbinding ecosystems, Ecol. Eng., 60, 116-125, 2013.

Zimmermann, U., Ehhalt, D., and Muennich, K. O.: Soil-water movement and evapotranspiration: Changes in the isotopic composition of the water, International Atomic Energy Agency, Vienna, 567-585, 1967. 